\title{
LA CRECIDA DE JUNIO DE 1933 DEL RÍO TURIA EN TERUEL: ESTIMACIÓN Y PUESTA EN VALOR
}

\author{
Miguel Sánchez Fabre \\ Alfredo Ollero Ojeda \\ Departamento de Geografía y Ordenación del Territorio. Universidad de Zaragoza \\ Instituto Universitario de Investigación en Ciencias Ambientales. Universidad de Zaragoza \\ msanchez@unizar.es, aollero@unizar.es
}

\section{RESUMEN}

Se analiza la crecida del río Turia en Teruel acaecida en junio de 1933. La prensa escrita se hizo eco de una relevante crecida del río Turia con importantes efectos en las proximidades de Teruel. A partir de esa evidencia, diversas fuentes documentales permiten averiguar sus causas, estimar su volumen y conocer sus principales efectos. Esa información se coteja con cálculos y fuentes cartográficas actuales para llegar a la conclusión de que se trata de una crecida histórica muy destacada, a tener muy presente en la evaluación de los riesgos actuales de inundaciones, y del enorme valor que la prensa escrita tiene para documentar crecidas en etapas de finales del siglo XIX y primera parte del siglo XX.

Palabras clave: crecida fluvial, inundación, prensa escrita, río Turia, Teruel.

\section{ABSTRACT}

We analyse the flooding of the River Turia around the city of Teruel (Aragon, Spain) that occurred in June 1933. Contemporary newspaper stories described the flood and its major effects. The use of various documentary sources enables an estimation of the causes of the flood, its volume, and main effects. This information is compared with current calculations and cartographic sources and we conclude that this was a significant historical flood and must be taken into consideration when assessing current flood risks. The study also highlights the enormous value of newspaper records in documenting floods in the late nineteenth and early twentieth centuries.

Keywords: Flash flood, flooding, newspaper, River Turia, Teruel.

Fecha de recepción: noviembre 2015.

Fecha de aceptación: noviembre 2016. 


\section{INTRODUCCIÓN Y ÁREA DE ESTUDIO}

Las crecidas son uno de los elementos que caracterizan el comportamiento de los cursos fluviales. Ayudan a establecer el grado de naturalidad de ese comportamiento, ya que en un régimen fluvial natural no pueden faltar, con una frecuencia variable. Cuando alcanzan un carácter extraordinario estas crecidas conllevan desbordamientos. El agua ocupa una parte de la llanura de inundación y cubre campos, explotaciones ganaderas, zonas industriales y áreas urbanizadas, al tiempo que se disipa su energía y aporta componentes beneficiosos para los suelos. Las afecciones producidas por las inundaciones están condicionadas, frecuentemente, por una excesiva exposición de bienes y personas, más que por ningún otro factor. Esa exposición se ha ido incrementando en las orillas de muchos ríos ante la sensación de falsa seguridad que la baja frecuencia de crecidas, la construcción de grandes embalses, o la ejecución de diferentes tipos de defensas (motas, diques, etc.) han producido.

Durante las últimas décadas se han mejorado los sistemas de alerta temprana y, en algunos casos, se han definido planes de gestión de crecidas en numerosas cuencas de países con recursos económicos. Esto ayuda a mitigar los efectos de las crecidas pero, en ningún caso, puede eliminarlas. Por otro lado, esta eliminación de las crecidas sería uno de los peores síntomas ambientales que podría presentar un curso fluvial.

El seguimiento y estudio de las crecidas se debe no sólo a que son parte de la esencia de los ríos, sino principalmente a los importantes daños socioeconómicos que pueden generar. Así, el comportamiento y los efectos de este tipo de fenómenos extremos han sido estudiados en ríos de ámbitos geográficos muy diferentes. En Europa Central se incrementa su atención a partir de las inundaciones ocurridas durante el verano de 2002 en la República Checa (río Moldava, río Danubio), o en Alemania (río Elba) y muy recientemente, 2013, en Austria, Alemania, República Checa y Polonia (Lehner et al., 2006; Barredo, 2007; Gaume et al. 2009; Petrow y Merz, 2009; Marchi et al., 2010; Glaser et al., 2010; Bormann et al., 2011; Kotlarski et al., 2012; Kundzewicz et al., 2012).

En la Península Ibérica son los ríos de las cuencas cantábricas y mediterráneas los que registran crecidas con mayor frecuencia y proporciones (García Ruiz et al. 1983, 1998, 2000 y 2001; Ollero, 1992, 2006, 2007; Carmona y Ruiz Pérez, 2000; Ibisate et al., 2000; Romero y Maurandi, 2000; Bescos, 2003; Ratto et al., 2003; Bescos y Camarasa, 2004; Losada et al., 2004; Ollero et al., 2004; Chastagnaret y Gil Olcina, 2006; López-Moreno et al., 2006; Olcina, 2006; Espejo et al., 2008; Espejo, 2008; Koutroulis y Tsanis, 2010; Acín et al., 2012; Tarolli et al., 2012; Serrano-Muela et al., 2013; Serrano-Notivoli et al., 2014; Marquínez et al., 2014; Terranova y Gariano, 2014).

Sin duda, la importancia de las crecidas como fenómeno natural y la relevancia de sus efectos sociales y económicos refuerzan la conveniencia de aplicar la Directiva Europea 2007/60/CE, relativa a la evaluación y gestión de los riesgos de inundación, traspuesta a nuestro país por el Real Decreto 903/2010. Estos documentos legales señalan la conveniencia de realizar una evaluación preliminar por riesgo de inundación, mapas de peligrosidad por inundaciones y mapas de riesgo de inundaciones, todo ello para concluir con la elaboración de Planes de gestión del riesgo de inundación a nivel de demarcaciones hidrográficas.

La información esencial de una crecida, en cuanto al volumen y la evolución, procede de los registros de nivel y caudal obtenidos en las estaciones de aforo, a través de la medición 
instrumentalizada de los niveles y caudales de ríos. Estos, en el caso de España, se recopilan en el Anuario de Aforos, donde la máxima desagregación temporal de la información es el dato diario. A ello hay que añadir la puesta en funcionamiento, a partir de la década 19801990, en diferentes Confederaciones Hidrográficas, del Sistema Automático de Información Hidrológica (SAIH), que supone un cambio sustancial en la disponibilidad de datos de caudal, ya que estos se obtienen en tiempo real y con un nivel de desagregación temporal horario, quinceminutal e incluso cincominutal.

Anuarios de Aforos y SAIH proporcionan una buena disponibilidad de información sobre la frecuencia y volumen de las crecidas durante la segunda mitad del siglo XX y los años transcurridos del siglo XXI. Aunque la toma de registros de aforos comenzó, teóricamente de forma sistemática, durante el año hidrológico 1911-12 en muchas cuencas y ríos, los datos son muy discontinuos a lo largo de la primera mitad del siglo XX, especialmente en lo relativo a su publicación en los anuarios de aforos. Por ello, para detectar crecidas y conocer sus efectos en este periodo y otros anteriores es conveniente recurrir a otras fuentes documentales. Entre ellas, la prensa escrita se ha mostrado como una fuente de información básica para el conocimiento de las crecidas durante la segunda mitad del siglo XIX y la primera mitad del XX. Las noticias aportadas por los periódicos, junto a otras fuentes documentales históricas, son la base del reconocimiento y estudio de numerosos eventos de crecidas acaecidos con anterioridad a la toma de datos instrumentales. Su conocimiento sirve para una mejor comprensión de la dinámica de los ríos, una más adecuada definición de probabilidades de crecidas y, por tanto, una más correcta definición del riesgo de inundaciones. Por tanto, se trata de una fuente de datos útil para la elaboración de los Planes de Gestión de Inundaciones que promueven la Directiva Europea de Inundaciones y el Real Decreto que la traspone al territorio español. Son numerosos los trabajos en los que se resalta el valor de la prensa escrita y se utiliza ésta para estudiar eventos concretos de crecidas o las producidas durante un determinado lapso de tiempo en un río o una región (Glaser y Stangl, 2003; Alberola, 2005; Barriendos y Rodrigo, 2006; Brázdil, Kundzewicz y Benito, 2006; Bürger et al., 2006; Demarée, 2006; Coeur y Lang, 2008; Pérez Morales y Gil, 2012; Galván et al., 2013).

En otro orden de cosas, los principales rasgos del comportamiento de los ríos Alfambra, Guadalaviar y tramo alto del Turia han sido definidos en algunos trabajos (Sánchez Fabre et al. 1986, 2008, 2013; Sánchez Fabre, 1993; Morell, 1999, 2001; Guillén, 2001; Del Valle et al., 2007).

A partir de los indicios obtenidos en distintas publicaciones periódicas de la época, nuestra hipótesis de partida es que en junio de 1933 el río Turia experimentó una crecida relevante, comparable en la zona próxima a Teruel a las mayores de las que se tiene conocimiento. El objetivo principal de este artículo es hacer una estimación de la dimensión y el alcance de este episodio de crecida. Además, estudiar sus causas y establecer una comparación con otras crecidas de las que hay registros correspondientes a las estaciones de aforo del propio río Turia y del Alfambra en Teruel.

El área de estudio quedará, por tanto, limitada a la zona más próxima a Teruel, incluyendo tanto el sector donde se produce la unión de los ríos Guadalaviar y Alfambra, como el tramo inicial del Turia (surgido de esta confluencia), su llanura de inundación y alguna de las ramblas afluentes. A este sector se refieren las noticias de desbordamiento del Turia que sirven de punto de partida a este trabajo. 


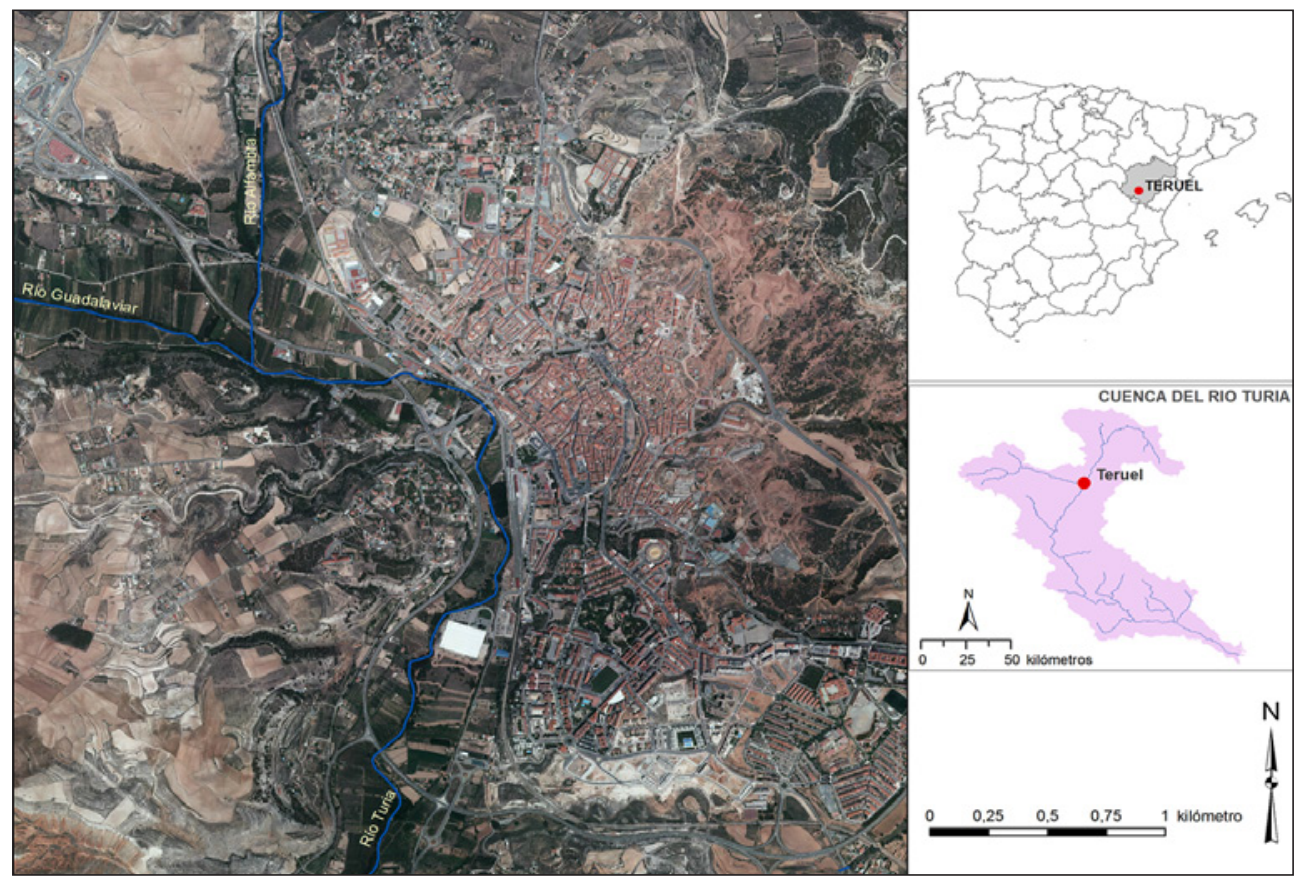

Fuente: Instituto Geográfico Nacional y Ministerio de Agricultura, Pesca, Alimentación y Medio Ambiente. Elaboración propia.

\section{MATERIALES Y MÉTODOS}

Muy diversas son las fuentes documentales y los métodos empleados para la elaboración de este trabajo. La existencia de esta crecida fue detectada por su referencia en el periódico $A B C$ del día 6 de junio de 1933, editado en Madrid. Por ello, se cita en primer lugar la consulta que se ha realizado de la prensa escrita, para localizar más referencias a esta crecida. Este seguimiento se ha realizado en la Biblioteca Virtual de Prensa Histórica de la Biblioteca Nacional y en la Biblioteca Virtual de Aragón de la Biblioteca de Aragón, pero también de forma presencial en las Hemerotecas Municipales de Teruel y Zaragoza. En estas hemerotecas no sólo se han buscado referencias a la crecida que nos ocupa, sino también se han examinado las alusiones a las principales crecidas de las que se tienen datos de caudal, medidos de forma instrumental, para analizar el seguimiento informativo realizado y poder comparar con el dado en su momento a la crecida de 1933. Para este seguimiento de las crecidas más recientes se han empleado los diarios escritos de mayor difusión en Aragón (Heraldo de Aragón, El Periódico de Aragón) y Teruel (Lucha-Diario de Teruel), ya que es en ellos donde existe mayor probabilidad de referencia.

Detectado el evento y viendo que se asociaba a precipitaciones intensas, la investigación se dirigió a establecer la posible causa de esta crecida. Para ello se examinó el "Resumen de observaciones meteorológicas de 1933” elaborado por la Sección de Climatología del Servicio 
Meteorológico Nacional perteneciente al Ministerio del Aire. Además, como fuente principal, los boletines del Servicio Meteorológico Español englobado en el Instituto Geográfico, Catastral y de Estadística; en ellos quedan recogidos tanto los datos de precipitación como la situación atmosférica existente. También resultan de gran interés los mapas de presión y temperatura que para las fechas de la crecida han sido modelizados, mediante modernos programas analíticos e interpolaciones, por NOAA (National Oceanic and Atmospheric Administation) y CIRES (Cooperative Institute for Research in Environmental Sciences, University of Colorado).

En el Archivo Municipal de Teruel se conservan los libros de registros de actas de sesiones del Ayuntamiento turolense, desde 1922. Su consulta ha permitido indagar si los efectos del desbordamiento del Turia tuvieron la suficiente trascendencia como para ser objeto de atención en las sesiones municipales. Se han obtenido algunos datos que complementan la información obtenida en otras fuentes.

Infructuosa ha sido la búsqueda de datos relativos a la crecida que nos ocupa en el Catálogo Nacional de Inundaciones Históricas, publicado por la Dirección General de Protección Civil y Emergencias. Su soporte digital facilita la consulta, pero lamentablemente este catálogo es muy parco e incompleto en relación con la cuenca alta del río Turia. Esto no hace sino ratificar la importancia que fuentes documentales como la prensa y los archivos tienen en el conocimiento de la dinámica de los ríos en épocas sin datos instrumentales.

La fuente más directa y completa para conocer el comportamiento hidrológico de los ríos Alfambra y Turia en la zona de estudio son las dos estaciones de aforo, pertenecientes a la red ROEA, ubicadas en la ciudad de Teruel. La situada en el río Alfambra (8027) registra la aportación de este curso fluvial prácticamente en su confluencia con el Guadalaviar. Acumula datos desde el año hidrológico 1912/13 hasta la actualidad. La estación de aforo del Turia (8015), localizada poco después de la confluencia de los ríos Alfambra y Guadalaviar ${ }^{1}$, posee datos desde 1911/12. Los valores correspondientes a estas estaciones están incluidos en el Sistema del Anuario de Aforos (sig.mapama.es/redes-seguimiento/visor.html) donde aparecen editados hasta el año 2011/2012, aunque con una interrupción entre 1931/32 y 1942/43. Las máximas instantáneas mensuales y anuales, así como los caudales medios diarios, son los registros, entre los recopilados en el Anuario, especialmente útiles para el seguimiento de las crecidas.

Además, estos dos aforos están incluidos en el Sistema Automático de Información Hidrológica del Júcar. Su puesta en funcionamiento en 1989 supone la disponibilidad de datos desde los años 90 con un nivel de desagregación horario o cincominutal, junto a la recopilación de datos de precipitación de igual temporalidad, que permiten un seguimiento y conocimiento mucho más detallado, además de en tiempo real, de los episodios de crecidas e inundaciones de los últimos 25 años. Los registros de estos aforos, procedentes tanto del Anuario de Aforos como del SAIH-Júcar, han permitido detectar las principales crecidas de la zona de estudio y evaluar sus volúmenes.

La consulta del documento "Evaluación preliminar del riesgo de inundaciones de la Demarcación Hidrográfica del Júcar” elaborado por la UTE Ofiteco-Pycsa-Arin, para la Confederación Hidrográfica del Júcar y la Dirección General de Sostenibilidad de la Costa y el Mar, incluye la zona de estudio dentro de los tramos preseleccionados para dicha evaluación. La define como área de riesgo potencial significativo con posibles afecciones a la salud humana (riesgo alto de daños inmediatos a personas), al patrimonio cultural y a las actividades económicas.

1 El río Guadalaviar recibe la denominación de río Turia a partir de su confluencia con el Alfambra. 
Esta evaluación forma parte de los trabajos realizados para la elaboración de la cartografía del Sistema Nacional de Cartografía de Zonas Inundables (SNCZI). Los tramos que atraviesan nuestra zona de trabajo están incorporados entre los ya analizados, dado ese carácter de área con riesgo potencial significativo. En dicha cartografía se incluye la superficie inundada en diferentes periodos de retorno. La disponibilidad de esta cartografía en formato shape nos permite, con la ayuda del Sistema de Información Geográfica ArcGIS 10.2, establecer una comparación entre los sectores de la llanura de inundación cubiertos por el agua en las crecidas de diferentes periodos de retorno y los inundados en junio de 1933, según se describe en prensa y actas municipales.

Para la estimación del caudal circulante en la crecida de junio de 1933 se ha seleccionado un punto de análisis, el Puente de Hierro, para el que se contaba con varias fotografías de la época y posteriores. Al no disponer de ninguna fotografía durante la crecida, se ha recurrido a referencias escritas en prensa, que señalan, con observaciones muy ajustadas de dos fuentes diferentes, a qué altura llegó el agua en dicho puente. A pesar de la destrucción durante la Guerra Civil de su tablero y barandillas, que han sido objeto de una última restauración en 2008, el puente permanece en pie y conserva sus vanos (a diferencia del original de Tablas, que podría haber sido otro punto de referencia interesante). Por ello, se ha procedido a un conjunto de mediciones en la actualidad que permitieran estimar el caudal que circuló por el puente en el momento de punta de crecida en 1933. Estas mediciones han sido ajustadas, a partir de la observación con el máximo detalle de las fotografías antiguas, a las condiciones del cauce en 1933. A continuación se ha aplicado el método geomorfológico que emplea la fórmula de Manning ${ }^{2}$ (Gallart, 1988; García Ruiz et al., 1996) a partir de la sección, radio hidráulico, pendiente y rugosidad, para lograr una estimación de caudal que, si bien puede contar con un evidente margen de error derivado de la inexistencia de mediciones ni datos morfológicos de aquella época, puede acercarse bastante a la realidad sirviendo para comprobar y demostrar las dimensiones y volúmenes que llegó a alcanzar aquel evento hidrológico. Esta metodología se ha mostrado muy útil en aplicaciones anteriores (Ollero, 2014).

\section{RESULTADOS Y DISCUSIÓN}

\section{III.1. La causa directa: precipitaciones}

Como en tantas ocasiones, el origen de este episodio de crecida fueron unas precipitaciones intensas y persistentes. Los boletines del Servicio Meteorológico Español (Servicio Geográfico, Catastral y de Estadística) aportan datos concretos sobre esas lluvias, que no sólo afectaron a la zona de estudio, sino que, como registran dichos boletines, fueron generalizadas en toda la Península Ibérica.

2 La fórmula de Manning se aplica para calcular caudales en cauces abiertos. Se enuncia:

$$
Q=\left(\frac{1}{n}\right) * S * R^{2 / 3} * J^{1 / 2}
$$

Q es el caudal en $\mathrm{m}^{3} / \mathrm{s} ; \mathrm{n}$ es el coeficiente de rugosidad del cauce; $\mathrm{S}$ es el área de la sección de la corriente en $\mathrm{m}^{2}$; $\mathrm{R}$ es el radio hidráulico en $\mathrm{m}$, siendo $\mathrm{R}=\mathrm{S} / \mathrm{p}$; $\mathrm{p}$ es el perímetro mojado en $\mathrm{m}$; J es la pendiente de la línea de carga. 
Figura 2

SITUACIÓN ATMOSFÉRICA DEL DÍA 5 DE JUNIO DE 1933.
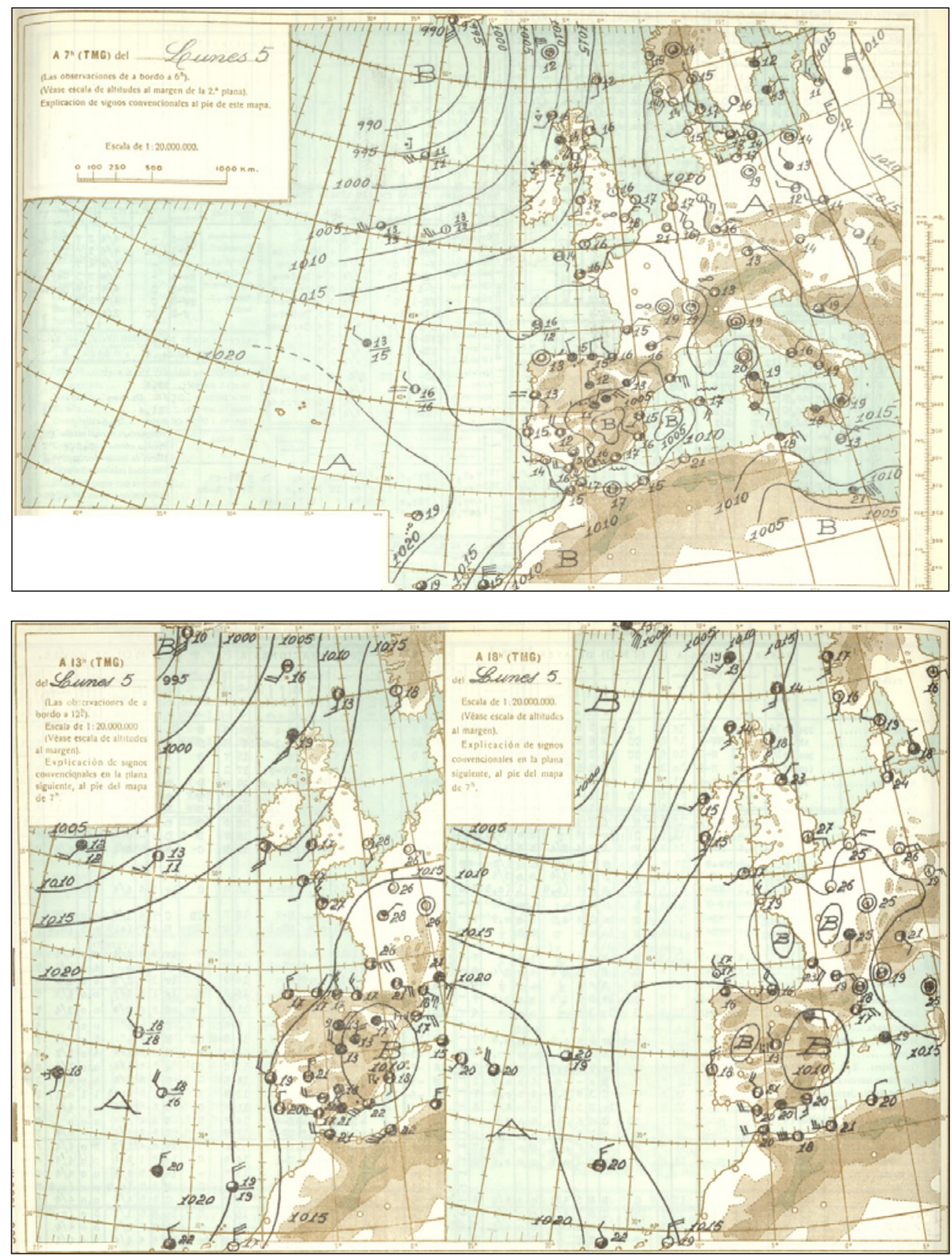

Fuente: Boletín del Servicio Meteorológico Español. 
Estas lluvias responden a una situación atmosférica dominada por la sucesión de borrascas procedentes del norte, con varios núcleos instalados sobre la Península Ibérica (Fig. 2). Así lo expresa el boletín del día 5: "Persisten sobre nuestra Península en su mitad Oriental los núcleos borrascosos que han producido abundantes lluvias en toda ella. Aparece una nueva borrasca en el Atlántico al Sur de Islandia y las altas presiones del Atlántico están al Sur de Azores" (Situación atmosférica a las 7 h. del lunes 5 de junio).

Los modelos realizados por NOAA y CIRES para reconstruir situaciones atmosféricas desde 1871 y disponibles en www.wetterzentrale.de reconstruyen para estas fechas una situación coincidente con la mostrada por el Boletín del Servicio Meteorológico de España. En el mapa de presión atmosférica del 4 de junio se ven núcleos de bajas presiones descolgándose sobre la Península; en el de temperaturas en altura $(850 \mathrm{hPa})$ se observan temperaturas frías asociadas a las bajas presiones y cómo la masa fresca descolgada comienza su entrada en la Península por el oeste (Fig. 3).

Figura 3

MODELIZACIÓN DE LA SITUACIÓN ATMOSFÉRICA DEL 4 DE JUNIO DE 1933.
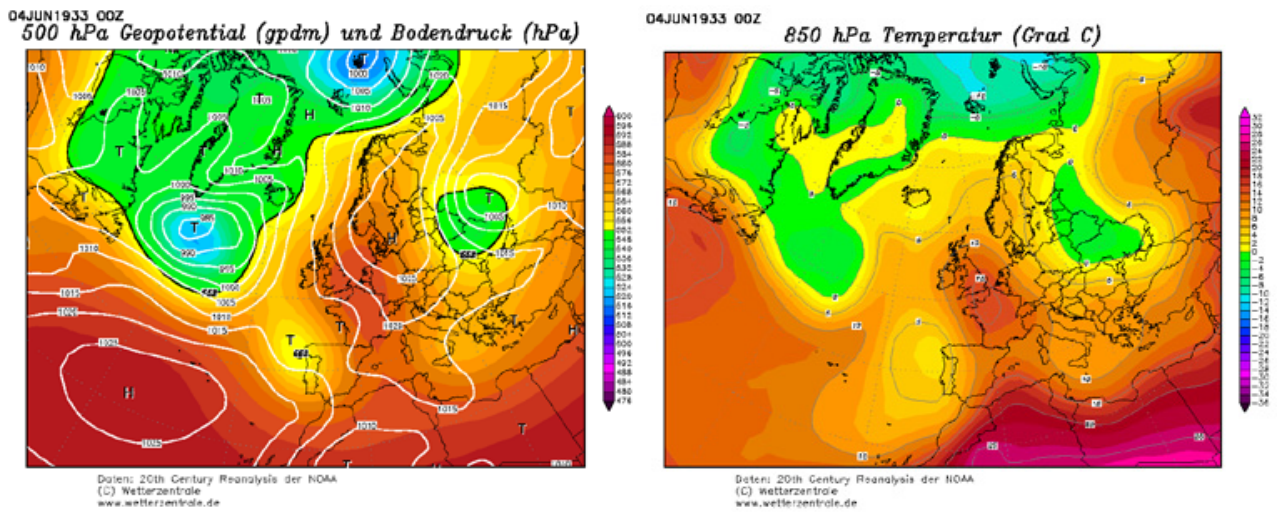

Fuente: NOAA (National Oceanic and Atmospheric Administration) y CIRES (Cooperative Institute for Research in Environmental Sciences, University of Colorado).

Fuente: www.wetterzentrale.de.

La lluvia se inició durante el día 3 de junio $(21 \mathrm{~mm})$, y se prolongó con intensidad considerable durante los días 4 y 5 de junio y con cantidades reducidas los días 6 y 7 . La mayor intensidad de la precipitación corresponde a la tarde del día 4 de junio y al día 5 , al totalizarse, en 36 horas, $78 \mathrm{~mm}$. Así, en tres jornadas, del 3 al 5 de junio, se acumularon $99 \mathrm{~mm}$ de lluvia (Fig. 4). Conviene señalar que este valor supone más del 25\% de la precipitación que anualmente se mide en el observatorio de Teruel.

Aunque estos datos corresponden exclusivamente al observatorio de Teruel, la generalización de las lluvias por la Península hace pensar en que también estuvieran extendidas por toda la cuenca. Además, refuerzan esta idea los datos medidos en estaciones del entorno de Teruel por el Servicio Meteorológico Nacional del Ministerio del Aire. Sobresalen entre ellos los 52,6 mm medidos el día 4 de junio en Dornaque, día en que este servicio eleva la lluvia 
en Teruel hasta los $63 \mathrm{~mm}$, y los 74,2 $\mathrm{mm}$ y $70 \mathrm{~mm}$ alcanzados respectivamente en Montalbán y Pozondón durante el día 5. Conviene indicar que estos observatorios se ubican en alineaciones montañosas que forman parte de la divisoria de la cuenca alta del Turia. También son reflejo de la abundancia de las precipitaciones los 102,6 mm recogidos el día 4 de junio en Villafranca del Cid, así como los 98,2 y los 134,2 medidos el día 5 en Segorbe y Zucaina, localidades en las que durante este mes de junio de 1933 se totalizaron 227,5 y 323,2 mm.

Figura 4

DISTRIBUCIÓN TEMPORAL DE LAS PRECIPITACIONES EN TERUEL DEL 3 AL 7 DE JUNIO DE 1933.

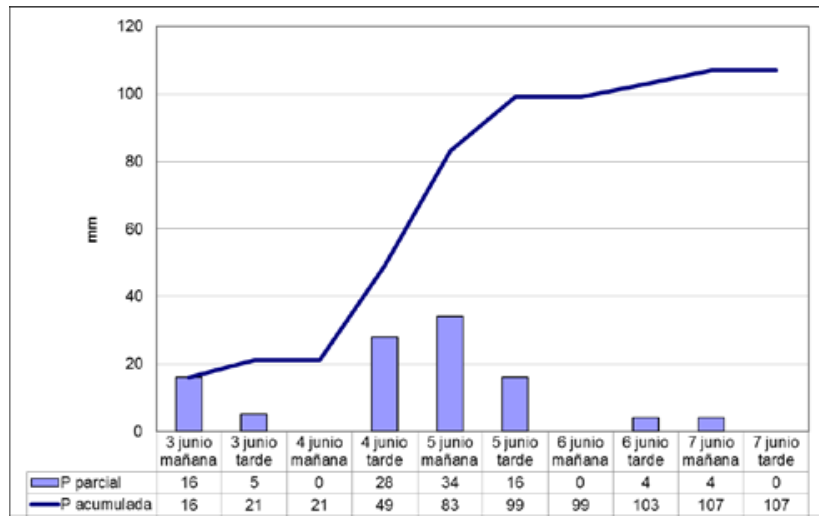

Fuente: Boletín del Servicio Meteorológico Español. Elaboración propia.

\section{III.2. La crecida de 1933 en el contexto de las crecidas de los ríos Alfambra y Turia en Teruel}

El Sistema del Anuario de Aforos ofrece datos, como ya se ha indicado, de una serie temporal muy amplia. Entre ellos, los valores de caudales máximos instantáneos mensuales y anuales, junto a los datos de caudal medio diario, permiten hacer un seguimiento bastante exhaustivo de los episodios de crecida que han afectado a los ríos Alfambra y Turia en el entorno de Teruel. Estos ya fueron analizados por Sánchez Fabre et al., 1986; Sánchez Fabre, 1993; Morell, 1999, 2001. El mayor número de días cuyo caudal medio supera el umbral de crecida se contabiliza entre febrero y junio. Eso sí, los registros más elevados de caudal instantáneo suelen medirse en verano y primera parte de otoño. En junio las crecidas son habituales y en un notable número de ocasiones se ha constatado la máxima instantánea anual durante este mes, pero no suelen alcanzar picos muy destacados.

En el presente trabajo se ha prolongado este análisis hasta fechas más recientes, seleccionando aquellas crecidas que durante la segunda mitad del siglo XX y los años transcurridos del XXI han alcanzado caudales punta más elevados. Es preciso apuntar la entrada en servicio, en torno a 1962, del Embalse del Arquillo de San Blas en el río Guadalaviar, ya que a partir de entonces puede atenuar los caudales de crecida del Turia en Teruel, salvo cuando su alimentación proceda casi exclusivamente del río Alfambra. El interés, en este caso, no está en analizar la evolución de estas crecidas sino en observar cuales de ellas han tenido reflejo 
en la prensa escrita. Para ello se han seleccionado aquellas crecidas del río Turia que en el aforo de Teruel marcaron un caudal punta superior a los $50 \mathrm{~m}^{3} / \mathrm{s}$ y las que en el aforo del Alfambra llegaron o superaron los $40 \mathrm{~m}^{3} / \mathrm{s}$. Hecha esta selección, recogida en la tabla 1 , se ha procedido a comprobar si se dejó constancia de ellas en los periódicos local, Lucha-Diario de Teruel, y regional, Heraldo de Aragón, de mayor difusión. También se revisó El Periódico de Aragón en relación con las crecidas constatadas desde el principio de su publicación en 1990. El objetivo es determinar si todas las crecidas tienen eco en la prensa escrita, al menos a partir de determinadas proporciones.

Se aprecia que, en el caso del Alfambra, las 5 crecidas que superan los $50 \mathrm{~m}^{3} / \mathrm{s}$ de caudal punta han sido recogidas en los periódicos. En el caso del Turia las menciones son más irregulares, si bien la mayor parte de las que superan el registro instantáneo de $60 \mathrm{~m}^{3} / \mathrm{s}$ se han plasmado en Heraldo de Aragón, en Diario de Teruel o en ambas publicaciones. Eso sí, la de mayor caudal punta sólo se menciona en Diario de Teruel y de la acaecida en octubre de 1962 no hay referencias.

Todo esto lleva a pensar que la crecida de junio de 1933 tuvo que alcanzar unas proporciones similares a las más importantes crecidas de Alfambra y Guadalaviar, ya que de ella se hizo eco no sólo la prensa local, sino diversos periódicos de otros lugares de la Península. A ello dedicaremos nuestra atención en posteriores apartados.

Tabla 1

REFERENCIAS EN PRENSA ESCRITA A LAS PRINCIPALES CRECIDAS DE LOS RIOOS ALFAMBRA Y TURIA CON REGISTROS DE AFORO

\begin{tabular}{|c|c|c|c|c|c|c|c|}
\hline & Fecha & $\begin{array}{l}\text { Caudal máx. } \\
\text { instant. } \mathrm{m}^{3} / \mathrm{s}\end{array}$ & $\begin{array}{l}\text { Caudal med. } \\
\text { diario } \mathrm{m}^{3} / \mathrm{s}\end{array}$ & $\begin{array}{l}\text { LUCHA - } \\
\text { DIARIO DE } \\
\text { TERUEL }\end{array}$ & $\begin{array}{l}\text { HERALDO DE } \\
\text { ARAGÓN }\end{array}$ & $\begin{array}{l}\text { EL PERIÓDICO } \\
\text { DE ARAGÓN }\end{array}$ & FICHAS CHJ \\
\hline \multirow{11}{*}{$\frac{\overleftarrow{\Upsilon}}{?}$} & $17 ? / 02 / 1960$ & 128,00 & 49,21 & $\mathrm{Si}$ & & & \\
\hline & 28/07/1972 & 111,27 & 16,70 & & $\mathrm{Si}$ & & \\
\hline & $14 / 08 / 1996$ & 110,64 & 8,77 & $\mathrm{Si}$ & $\mathrm{Si}$ & $\mathrm{Si}$ & \\
\hline & 02/09/1981 & 82,46 & 4,60 & & $\mathrm{Si}$ & & \\
\hline & $24 / 08 / 2002$ & 73,91 & 12,83 & $\mathrm{Si}$ & $\mathrm{Si}$ & & \\
\hline & $14 ? / 10 / 1962$ & 61,00 & 18,52 & & & & \\
\hline & 19/08/1998 & 60,52 & 11,08 & & $\mathrm{Si}$ & & \\
\hline & $14 ? / 10 / 1957$ & 60,20 & 49,21 & $\mathrm{Si}$ & $\mathrm{Si}$ & & Si (pero no Teruel) \\
\hline & 20-23?/12/1958 & 58,00 & 49,21 & & & & \\
\hline & $27 ? / 05 / 1962$ & 54,80 & 20,28 & & & & \\
\hline & 15/09/1999 & 49,00 & 22,88 & $\mathrm{Si}$ & $\mathrm{Si}$ & $\mathrm{Si}$ & \\
\hline \multirow{8}{*}{ 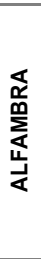 } & $17 ? / 08 / 1950$ & 138,50 & 6,27 & $\mathrm{Si}$ & $\mathrm{Si}$ & & \\
\hline & 9?/08/1981 & 132,12 & 2,44 & $\mathrm{Si}$ & $\mathrm{Si}$ & & \\
\hline & $14 / 8 / 1996$ * & 112,00 & 4,19 & $\mathrm{Si}$ & $\mathrm{Si}$ & & \\
\hline & 1?/07/1955 & 69,57 & 3,16 & & $\mathrm{Si}$ & & \\
\hline & $13 ? / 10 / 1957$ * & 51,95 & 21,54 & Si & $\mathrm{Si}$ & & Si (pero no Teruel) \\
\hline & 25/07/1969 & 45,43 & 13,91 & & & & \\
\hline & 27?/09/1948 & 40,00 & 2,12 & & & & \\
\hline & $26 ? / 05 / 1956$ & 39,41 & 15,94 & & & & \\
\hline
\end{tabular}

* la crecida fue muy destacada tanto en el conjunto del Turia como en el Alfambra

? el interrogante tras el número del día indica la jornada en que probablemente se registró el pico, ya que los Anuarios de Aforos sólo señalan mes y año

Aún no se editaba en estas fechas

Elaboración propia. 
También aparece reflejado en la tabla el hecho de que en el Catálogo Nacional de Inundaciones Históricas, publicado por la Dirección General de Protección Civil y Emergencias, entre las fichas correspondientes a la Demarcación del Júcar, sólo aparece referencia de la excepcional crecida de 1957 y esta se limita a los efectos en Valencia, por lo que no hay ninguna alusión al tramo alto de la cuenca. Esto demuestra la necesidad de revisar y completar este catálogo, teniendo en cuenta no sólo los registros obtenidos en los aforos, sino también las referencias en diferentes documentos escritos, especialmente los periódicos. Así se precisaría y podría matizar mucho más la definición de las áreas con potencial riesgo de inundación.

\section{III.3. Referencias y efectos de la crecida de junio de 1933}

Como se acaba de apreciar, incluso algunas de las crecidas más relevantes de los ríos Alfambra y Turia no se reflejaron siquiera en la prensa local y regional. Sin embargo, las referencias a la crecida de estos ríos de junio de 1933 incluyen no sólo esta prensa local y regional, sino también diversos periódicos de ámbito nacional o de diversas provincias españolas.

Entre la prensa local hay noticias relativas a la crecida en Acción y en República, periódicos destacados de la época conservados en la Hemeroteca de Teruel y digitalizados en la Biblioteca Virtual de Aragón. Aluden al episodio de inundaciones y sus efectos desde el día 6 al 10 de junio. En el ámbito regional destaca la información ofrecida por Heraldo de Aragón, ya entonces el de mayor difusión en esta comunidad, que recoge diariamente datos entre el 6 y el 9 de junio.

El diario $A B C$, de ámbito nacional y publicación en Madrid, significa la importancia de la crecida en su edición del día 6 de junio. También alude a la crecida el periódico La Libertad, igualmente editado en Madrid y de difusión nacional. Finalmente, un buen número de diarios de carácter local pero pertenecientes a diversas provincias, fundamentalmente del ámbito mediterráneo, se hacen eco de este episodio hidrológico: Diario de Alicante, El Día y El Luchador, en Alicante; La Correspondencia, en Valencia; El Defensor de Córdoba y La Voz, en Córdoba; Diario de Almería, en Almería; La Voz de Menorca, en Menorca.

Varios de ellos aluden al carácter muy prolongado de las precipitaciones, con más de 40 horas ininterrumpidas de lluvia. El inicio de estas precipitaciones se concreta a primera hora de la tarde del sábado, día 3 de junio, con una fuerte granizada, y alcanzan su mayor intensidad desde la madrugada del domingo a la del lunes, periodo que coincide con los mayores registros recogidos en el Boletín del Servicio Meteorológico Español ya analizados. También se refieren a la presencia de nieve en las sierras de Albarracín, Javalambre y Gúdar.

Globalmente aluden al desbordamiento de los ríos Alfambra, Guadalaviar y Turia, y plasman una serie de efectos más concretos provocados por la crecida de estos ríos. Entre ellos destacan:

- Arrastre de árboles, animales y restos de edificaciones (tapias).

- Inundación de las vegas y destrucción de cosechas. Dado el mes en el que se produce la crecida, cereales como la avena estaban recién cosechados, por lo que en muchos casos fueron arrastrados por la corriente, en tanto que la recolección del trigo estaba ya próxima, por lo que la crecida arruinó una parte importante de la cosecha. Las cosechas de remolacha, verduras y árboles frutales fueron arrasadas también en muchos campos. Esta inundación de vegas no sólo se produjo en el sector próximo a Teruel, sino que la prensa la extiende a amplios tramos del río Alfambra (Alfambra, Peralejos, Cuevas Labradas, Villalba Baja, Tortajada) y a otros del Turia aguas abajo de Teruel (Villaspesa, Libros). 
- Tráfico interrumpido en la carretera de Zaragoza y dificultad en la circulación de trenes. Tanto un tramo de esa carretera como otro de las vías de ferrocarril, además de la propia estación ferroviaria, se asientan en la llanura de inundación del Turia. El periódico Acción indica que faltó sólo un metro más de ascenso de las aguas para que la estación se inundara.

- Grandes destrozos en la avenida de Zaragoza. Afortunadamente el nivel de ocupación de esta zona por viviendas y otros edificios de distintos usos era sensiblemente inferior al existente en la actualidad.

- La lámina de agua no sólo alcanzó la avenida y la carretera de Zaragoza sino que ocupó la plazuela ubicada frente al Convento de San Francisco, que "quedó convertida en un gran lago" (Acción, 6/6/1933). Para impedir la entrada del agua en la iglesia y el colegio de los Franciscanos, así como en las casas cercanas hubo que levantar un muro de hasta más de medio metro para tapiar las puertas.

- Por la margen opuesta, la derecha, la inundación llegó hasta el lavadero público y el edificio de abastecimiento de Aguas Potables de Guadalaviar.

- La lámina de agua cubrió las arcadas inferiores del Puente de Hierro, situado en esta zona del Convento de los Franciscanos, y apenas quedó a medio metro de enrasar con su tablero (Acción) o "llegó a lamer el piso del puente" (República).

- El denominado Puente de Doña Elvira o Puente de Tablas fue arrastrado por la corriente, tras chocar contra su machón central un grueso tronco de árbol.

- Diferentes periódicos llegan a cifrar el ascenso de la lámina de agua con respecto al nivel ordinario. Acción y Heraldo de Aragón la sitúan en 6 metros, en tanto que La Libertad lo eleva a 8 y República hasta $9 \mathrm{~m}$ en algunos puntos. Resulta difícil dar verosimilitud a estas cifras si tenemos presente que los registros de nivel más elevado medido en la estación de aforo del Turia, ubicada dentro de la zona de estudio, es de 3,9 m en 1914 y 3,75 m en 1916, rondándose los 3 metros en 1920, 1923 y 1924. Por su parte, en el aforo del Alfambra, también inmerso en la zona de trabajo, se alcanzaron los 4,8 m en agosto de 1914 y se superaron los 3,5 m en 1913 (Tabla 2). En bastantes de estos casos no aparece el correspondiente registro de caudal medio diario en el Anuario de Aforos. Entre aquellos que tienen valor tanto de nivel como de caudal destacan las crecidas de 1920, 1923 y 1924, ya que en ellas se superaron $\operatorname{los} 100 \mathrm{~m}^{3} / \mathrm{s}$ de caudal medio diario en el aforo del río Turia. Las alusiones a que hacía 20 años que no se producía una crecida de magnitud similar llevarían a comparar esta crecida con las de 1913, 1914, 1917, que alcanzaron registros muy significativos. Por otro lado, las referencias a la altura del agua en relación con el Puente de Hierro, hacen pensar en una columna de agua en torno a 3 metros por encima del nivel ordinario del río. Esta altura y la proximidad de la estación de aforo del Turia, a 150 m aguas abajo de este puente, nos lleva a registros muy próximos a los apuntados y superiores a los alcanzados por las principales crecidas de este río en la segunda mitad del siglo XX e inicios del XXI. Ahora bien, en relación con la diferencia de nivel del agua entre las crecidas anteriores a 1950 y posteriores hay que considerar dos importantes matices: la ya mencionada construcción del Embalse del Arquillo de San Blas y sus posibles efectos; y, sobre todo, el cambio en las estaciones de aforo, ya que en 1943 entran en funcionamiento los aforos con sección regularizada y limnígrafo frente a la medición anterior en escala limnimétrica y sección natural (Mateu et al., 2012). Esto 
último determina que no se pueda establecer comparación entre los niveles anteriores y posteriores a dicho cambio en la estación de aforo.

Tabla 2

NIVELES MÁXIMOS ALCANZADOS POR LAS AGUAS DE LOS RIOOS ALFAMBRA Y TURIA EN LA PRIMERA PARTE DEL SIGLO XX

\begin{tabular}{|c|c|c|c|c|c|c|c|c|c|c|c|c|}
\hline & 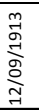 & 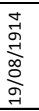 & 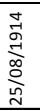 & 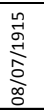 & 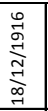 & 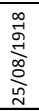 & 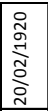 & 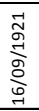 & 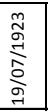 & 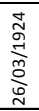 & 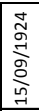 & \\
\hline Nivel Alfambra (m) & 3,7 & 4,3 & 4,8 & 3 & & 3 & 3,3 & 3 & 3,1 & & & \\
\hline Nivel Turia (m) & 3,1 & 3,4 & 3,9 & 2,9 & 3,75 & & 3,02 & & 2,96 & 3 & 3 & 2,8 \\
\hline
\end{tabular}

Fuente: Anuario de Aforos. Elaboración propia.

- Inundación y desalojo de casas próximas al Puente de Tablas y la zona de la estación del ferrocarril. También aguas abajo de la zona de estudio, la crecida del río Turia obligó a evacuar las casas de la parte baja del pueblo de Libros.

Varios de los periódicos consultados dejan constancia de la importancia que también tuvo la crecida en Valencia (VV.AA., 2012), con inundación de campos y desalojo de viviendas. Además, evidencian crecidas en otros muchos ríos próximos como Jiloca, Guadalope y Martín. No debe olvidarse el carácter generalizado de las precipitaciones en toda la Península.

Algunos de los datos recogidos por diferentes diarios nos permiten reconocer algunos rasgos de la evolución de la crecida. Desde luego ésta fue rápida, como suele ser característico de los ríos Alfambra, Guadalaviar y Turia. Parece que comenzó a evidenciarse a última hora de la tarde del domingo 4 de junio y el día 6 ya se apunta un descenso grande y la tendencia a la normalización del caudal. El pico de la crecida se habría producido a lo largo de la mañana del día 5, en algún momento entre las 8 y las 14 h.

Las Actas de Sesiones del Ayuntamiento de Teruel ratifican estos efectos y promueven acciones ante la magnitud de los daños producidos por la crecida. Hacen especial hincapié en las pérdidas de las cosechas hortícolas y de cereales. Además, en la necesidad de reparar el Puente de Doña Elvira o de Tablas. A este respecto, el Acta del 3 de mayo de 1933 recoge el ruego de un concejal a la Presidencia de que se coloquen dos tablones en el Puente de Tablas para evitar cualquier desgracia con motivo de la abertura allí existente. Esto nos podría llevar a suponer que el puente ya estaba puntualmente dañado con anterioridad a la llegada de la crecida. Eso sí, tras la crecida de junio ya no se habla de reparación puntual, sino de reconstrucción del puente. En las sesiones del 17 de junio y del 26 de julio de 1933 se consignan gastos para la reconstrucción de una palanca provisional en el puente de Tablas. Y es en la sesión del 30 de agosto cuando se plantea su reconstrucción: "Vista la propuesta del Concejal Sr. Bernad ex-delegado de Caminos con referencia a la reconstrucción del Puente de Doña Elvira ó de tablas, y un particular de la variante del último trozo del Camino de Teruel a Cubla, se acordó después de una breve observación de Secretaría sobre la imposición de las contribuciones especiales, que se reconstruya dicho puente a base de cemento por medio de una losa de hormigón armado aprovechando la obra existente en la actualidad, con imposición de las contribuciones especiales a los propietarios a quienes afecte la mejora, debiendo 
procederse por la Sección de Arquitectura a confeccionar el correspondiente proyecto y presupuesto, que se remitirá nuevamente a la Comisión de Fomento para su trámite y estudio, ...”.

Por su parte, dada la gravedad de los efectos provocados por la crecida, el Ayuntamiento reacciona de inmediato y solicita ayudas para los afectados. Así, en la sesión del día 5 de junio, fecha del pico de la crecida, tras la intervención de varios de los componentes de la corporación municipal "se acordó por unanimidad que en atención a la crítica situación en que quedan los labradores y propietarios de fincas rústicas de este término municipal, como consecuencia de los temporales de lluvia y granizo que han motivado el desbordamiento de los ríos Alfambra, Guadalaviar y Turia, inundando la huerta de esta capital y de las barriadas con pérdida de las cosechas hortícolas y en gran parte la de cereales en el campo, y con objeto de remediar la situación angustiosa en que quedan los propietarios de las fincas inundadas, muchos de los cuales por ser pequeños arrendatarios quedan en la indigencia, que se instruya el oportuno expediente de calamidad pública solicitando del gobierno de la República la concesión de auxilios económicos con que remediar en parte la situación crítica en que quedan muy especialmente los moradores de la Barriada de Villaspesa, cursando con la urgencia que el caso requiere telegramas a los Excelentísimos señores Presidente del Consejo de Ministros y Ministro de Agricultura, y facultando a la Alcaldía para que tome las medidas conducentes a tal fin en beneficio de las causas que motivan este acuerdo".

El contenido de los mencionados telegramas, así como la instancia remitida al Gobierno Civil para que la curse al Ministro de Agricultura, Industria y Comercio, están textualmente recogidas en el ejemplar del diario Acción correspondiente al día 7 de junio. En todos ellos se incide especialmente en la solicitud de auxilio económico para los damnificados. Además, se habilita un horario, de 12 a $13 \mathrm{~h}$. de todos los días laborables comprendidos entre el 8 y el 13 de junio, para que los afectados presenten declaración jurada en el impreso que se les facilitará en el propio Ayuntamiento. El mismo diario Acción da fe el día 8 de que numerosos vecinos de Teruel y sus barrios han empezado a acudir a la casa consistorial para hacer este trámite.

Sólo una semana después, el acta de la sesión del día 12 de junio recoge la recepción de un telegrama del Director General de Agricultura, contestando al que se le remitió sobre los últimos temporales en solicitud de auxilio para los damnificados. El contenido de este telegrama se recoge en el diario República: "Con esta fecha telegrafio a ingeniero jefe sección Agronómica Teruel para que emita informe sobre cuantía daños ocasionados por desbordamiento ríos Alfambra y Turia”.

\section{III.4. El Sistema Nacional de Cartografía de Zonas Inundables (SNCZI)}

La Directiva europea 2007/60 sobe evaluación y gestión de riesgos de inundación, así como su trasposición a la legislación española a través del Real Decreto 903/2010, señalan entre las tareas a realizar por los estados europeos tanto la evaluación preliminar del riesgo de inundación en sus ríos como la elaboración de mapas de peligrosidad por inundaciones y de riesgo de inundación.

Las distintas Demarcaciones hidrográficas han comenzado esas tareas cartográficas. Los resultados se han centralizado en el Sistema Nacional de Cartografía de Zonas Inundables (SNCZI), que se puede consultar a través del visor cartográfico de zonas inundables en la página web del Ministerio de Agricultura, Pesca, Alimentación y Medio Ambiente. 

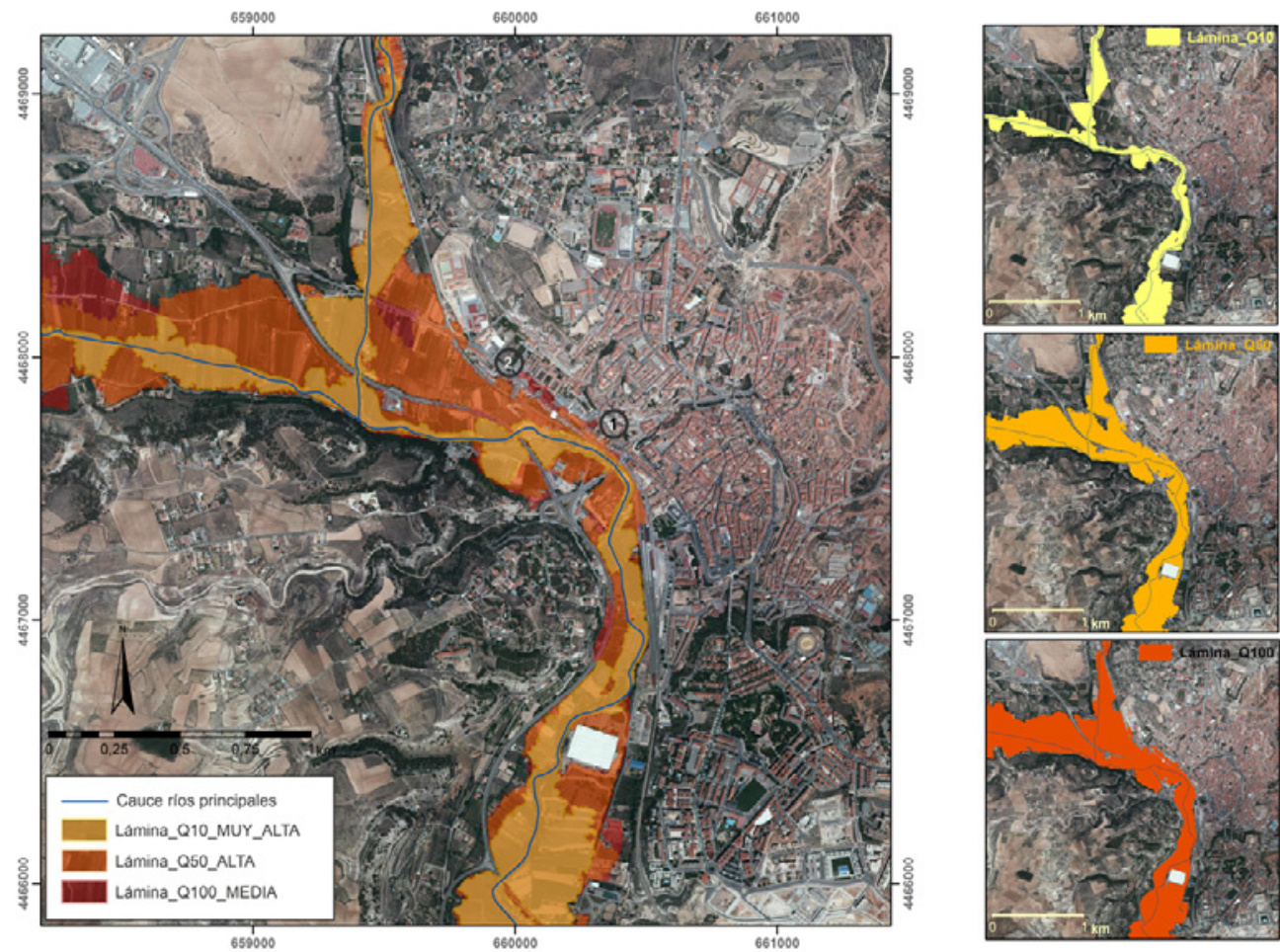

Fuente: Magrama-SNCZI. Elaboración Propia.

Dentro de las zonas analizadas y cartografiadas se encuentran las llanuras aluviales de Alfambra, Guadalaviar y Turia en la zona próxima a Teruel. Esta zona ha sido definida como área de riesgo potencial significativo de inundación. En ella se han establecido las zonas inundables en diferentes periodos de retorno y, por tanto, con distinto grado de probabilidad. En el SNCZI se recoge la cartografía de las zonas inundables con un periodo de retorno de 10, 50, 100 y 500 años, definiéndolas, respectivamente, como de muy alta probabilidad de inundación, alta, con probabilidad media u ocasional y con probabilidad baja o excepcional.

En el presente trabajo se han considerado las láminas de agua correspondientes a las crecidas de frecuencia muy alta (Q10), alta (Q50) y media (Q100). Todas ellas se han representado en la figura 5, superpuestas a la ortofoto de 2012. Se han representado tanto de manera individualizada, a escala 1:50.000, como superpuestas también entre ellas, a escala 1:17.500. La gran diferencia existente entre el territorio anegado por la inundación de frecuencia muy alta con respecto al cubierto por los desbordamientos de frecuencia alta y media se aprecia de ambas formas. Sin embargo, las crecidas con periodos de retorno de 50 y de 100 años inundan un área amplia y no demasiado diferente. 
Lo que se pretende aquí es relacionar el espacio ocupado por estas láminas de agua con los efectos descritos en la crecida de 1933. La zona de la estación y del puente de tablas, que se encuentran prácticamente en el mismo sector del río, se ven bastante afectadas incluso por las crecidas de menor importancia, aquellas consideradas como de frecuencia muy alta (Q10). La inundación de la vega y los consiguientes daños en las cosechas también son comunes a las crecidas de diferentes frecuencias, desde muy alta a baja. Ahora bien, la superficie de campos anegados es prácticamente el doble en una crecida de frecuencia alta, con periodo de retorno de 50 años, que en una de frecuencia muy alta, correspondiente al periodo de retorno de 10 años. En cambio, la zona inundada por la crecida de 100 años no es mucho más amplia que la cubierta por la de 50. Dada la magnitud de los daños, señalados tanto en la prensa como en las actas municipales, que justificarían la solicitud de ayuda al gobierno de la República, cabe pensar que la crecida no fue de las más habituales sino de aquellas en las que la lámina de agua ocupa la mayor parte de la llanura de inundación.

No obstante, hay otros efectos más clarificadores. La cartografía del SNCZI nos muestra que la crecida con retorno de 10 años no llega a afectar a la avenida de Zaragoza, tampoco a la carretera, mucho menos a la plaza ubicada delante del convento de San Francisco ni a esta iglesia, y apenas afecta a las vías del tren. Sin embargo, la lámina de inundación correspondiente a la crecida de 50 años cubre una parte de la avenida de Zaragoza (señalada con un 2 en la figura 5), un tramo importante de las vías del ferrocarril y de la carretera y alcanza la iglesia-convento de San Francisco (señaladas con un 1 en la figura 5), por tanto también la plaza situada entre ella y el río, así como las casas aledañas. La inundación con periodo de retorno de 100 años repetiría los efectos señalados, pero ampliaría el tramo de la avenida y carretera de Zaragoza sumergido, además de los aledaños del convento-iglesia de los franciscanos cubiertos de agua. Todos estos efectos son descritos reiteradamente por las fuentes consultadas, de modo que la magnitud de la crecida de 1933 quedaría englobada al menos como de una avenida con periodo de retorno de 50 años, e incluso podría llegar a identificarse con las crecidas de retorno de 100 años.

Es también relevante indicar el muy distinto grado de urbanización existente en el año 1933 en esta parte de la ciudad de Teruel y, muy concretamente, en el entorno de la avenida de Zaragoza. Como referencia tenemos la mencionada ortofoto de 2012 y la fotografía aérea del vuelo americano de 1945-46, serie A, incluidas en la figura 6. Allí se puede ver cómo en el momento de la crecida no existían apenas casas en el entorno de la avenida, esencialmente en el flanco más próximo al río, ni tampoco las instalaciones deportivas que hoy en día se localizan entre la citada avenida y la orilla derecha del Turia. Se aprecia por tanto un incremento sustancial de la exposición que, sin duda, en la actualidad incrementaría los daños producidos por una crecida que llegase a Teruel con una magnitud similar a la de 1933.

El SNCZI incluye un mapa de caudales máximos, donde se establecen los caudales máximos instantáneos que podrían llegar a alcanzarse, para distintos periodos de retorno, en diferentes tramos de ríos. Los valores determinados para el río Turia en Teruel se recogen en la tabla 3, donde también se anotan los calculados por el método de $\mathrm{Gumbel}^{3}$ con datos de máximos instantáneos anuales, procedentes del Anuario de Aforos, correspondientes a 55 años englobados entre 1956/57 y 2011/12.

3 Por el método de Gumbel se calcula el "valor máximo" alcanzado, para un determinado periodo de retorno, por un episodio de precipitación o de crecida. Se expresa: $\mathrm{x}=\mathrm{x}_{\mathrm{m}}+\mathrm{Dx}$. $\mathrm{x}$ es el valor máximo para un determinado periodo de retorno (T); xm es la media de la serie dada de valores máximos; Dx es la desviación respecto de la media. 
Como se aprecia, en ambos casos los resultados obtenidos son muy similares. Lo más destacable es que, con un periodo de retorno de 25 años, se superan $10 \mathrm{~s} 90 \mathrm{~m}^{3} / \mathrm{s}$ de caudal máximo instantáneo, y el pico de las crecidas con retorno de 50 años sobrepasa los $100 \mathrm{~m}^{3} / \mathrm{s}$. Se puede, por tanto, señalar que la crecida de 1933 casi con seguridad superó los $100 \mathrm{~m}^{3} / \mathrm{s}$, lo que la sitúa como una de las crecidas de mayor magnitud del río Turia en Teruel. Este valor sólo se ha alcanzado en tres ocasiones durante el periodo comprendido entre 1956/57 y 2011/12 del que existen registros de caudales máximos instantáneos.

Tabla 3

CAUDALES MÁXIMOS INSTANTÁNEOS ALCANZADOS CON DIFERENTES PERIODOS DE RETORNO

\begin{tabular}{|c|c|c|}
\hline & \multicolumn{2}{|c|}{ Caudal Máximo Instantáneo $\left(\mathbf{m}^{3} / \mathbf{s}\right)$} \\
\hline $\begin{array}{c}\text { Periodo de retorno } \\
(\mathrm{años})\end{array}$ & Mapa de caudales máximos SNCZI & Gumbel \\
\hline 100 & 139 & 126 \\
\hline 50 & & 110,2 \\
\hline 25 & 91 & 94,3 \\
\hline 10 & 66 & 72,8 \\
\hline 5 & 50 & 55,8 \\
\hline 2 & 29 & 30,1 \\
\hline
\end{tabular}

Fuente: Mapa de caudales máximos del Ministerio de Agricultura, Alimentación y Obras Públicas y elaboración propia.

\section{III.5. Estimación de caudales circulantes}

Aunque no estén publicados en el Anuario de Aforos, es posible que existan datos de nivel y caudal medio diario de los aforos de los ríos Alfambra y Turia en Teruel para el periodo de la crecida que analizamos, si bien, a pesar de diferentes intentos, no hemos conseguido acceder a ellos. Nos hace pensar en esa posibilidad la afirmación de Mateu et al. (2012) sobre la existencia de los mismos, al menos en numerosas estaciones de aforo, para el periodo en que no se publica el Anuario de Aforos. También parece confirmarlo la información existente en las hojas de "Resumen de caudales medios y extremos correspondientes a los años 1932-1942" de las dos estaciones, recogidas por el Servicio de Aforos de la Confederación Hidrográfica del Júcar. En ellas se puede apreciar que el Alfambra alcanzó en Teruel un caudal medio diario máximo, en junio de 1933 , de $33,9 \mathrm{~m}^{3} / \mathrm{s}$, en tanto que, tras la confluencia de Alfambra y Guadalaviar, el Turia se quedó en $31,6 \mathrm{~m}^{3} / \mathrm{s}$. Además, para ambas estaciones de aforo se indica la existencia de registros en 28 de los 30 días del mes.

A partir de estos datos se pueden aventurar algunas hipotéticas ideas:

- El dato del caudal medio diario máximo es muy destacado, por lo que si corresponde al día del pico de la crecida o a los días inmediatamente posteriores refrendaría la importancia del episodio de crecida. 
- La comparación de los registros de caudal medio diario máximo del Alfambra y el Turia lleva a pensar que es el primero de estos ríos el que en mayor medida generó el elevado caudal. Por tanto, si estos pudieran asociarse definitivamente al evento de crecida, su aportación procedería básicamente del Alfambra.

- La falta de 2 días de registro de caudal podría perfectamente estar asociada a la crecida. La inundación provocada podría haber impedido el acceso a los aforos y de ahí la falta de datos. Esencialmente en la segunda década del siglo XX, son varias las ocasiones en que no existen datos de caudal, aunque si de nivel, el día del pico de diversas crecidas e incluso algunos días antes y después de esa jornada.

Figura 6

DETALLE ZONA INUNDADA. DIFERENCIAS DE EXPOSICIÓN ENTRE ORTOFOTO 2012

(EN COLOR) Y FOTO 1945-46 (EN BLANCO Y NEGRO)
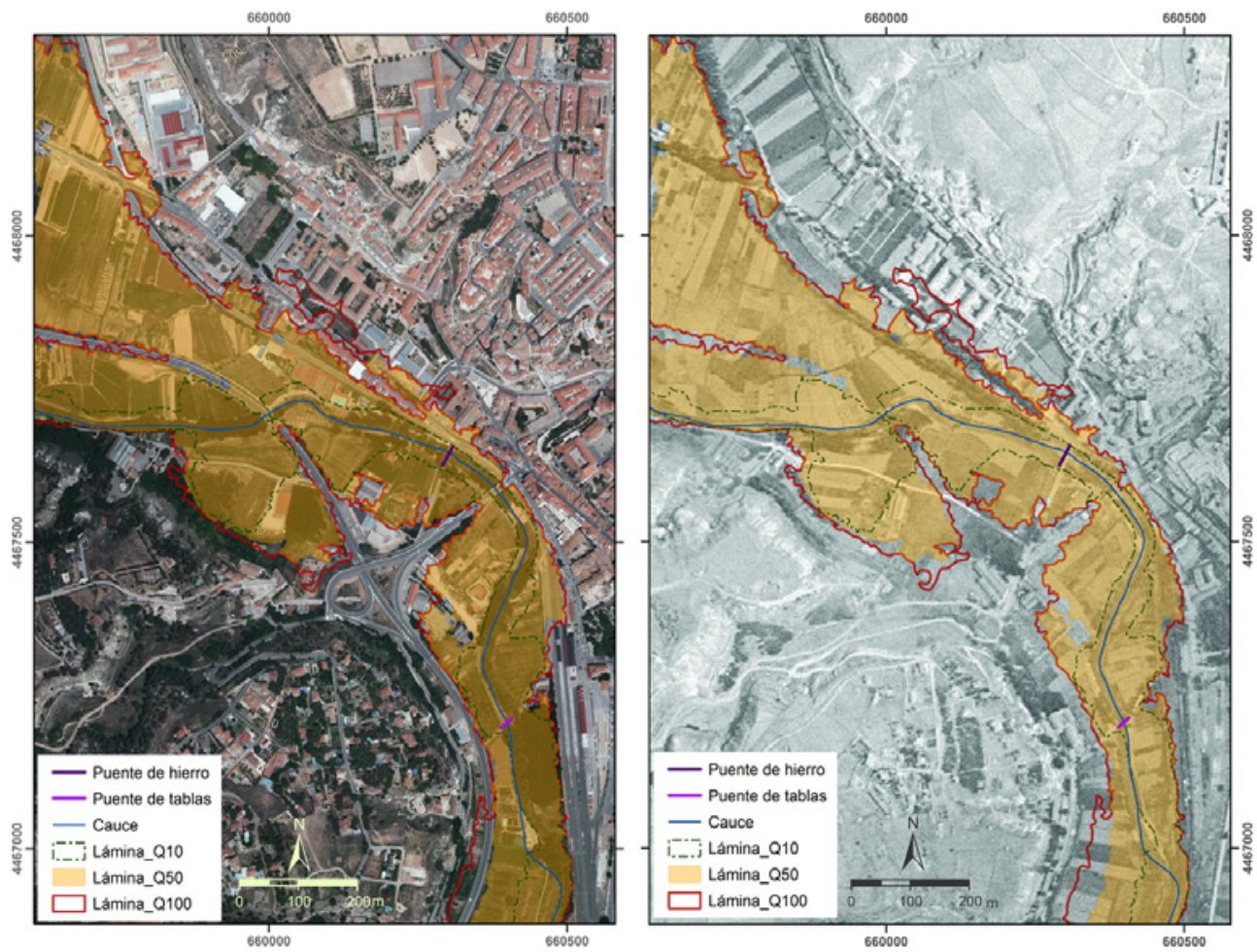

Fuente: IGN, Instituto Geográfico de Aragón, SNCZI. Elaboración propia.

En este trabajo se ha efectuado una estimación del caudal máximo que discurrió por el río Turia durante este episodio de crecida, partiendo de la afirmación de que el agua apenas quedó a medio metro de enrasar con el tablero del Puente de Hierro (Acción), confirmada por la referencia de que la crecida "llegó a lamer el piso del puente” (República). 
A partir de esa referencia, se ha medido la sección actual en el puente de Hierro (figura 7) y, a partir de las fotografías antiguas, se ha estimado la sección en 1933. La sección actual incluyendo los arcos de piedra laterales es de 79,37 $\mathrm{m}^{2}$. Con un perímetro de mojado de 42,8 $\mathrm{m}$, el radio hidráulico es, por tanto, de 1,85 . La pendiente local es de $0,0030675 \mathrm{~m} / \mathrm{m}$ y la rugosidad (n de Manning) puede estimarse en 0,063, relativamente alta por la presencia de vegetación herbácea en la margen izquierda (derecha en la foto), por la rugosidad interna de la propia crecida y por el efecto de obstrucción del puente. De acuerdo con estos valores y aplicando la fórmula de Manning, resulta que en la actualidad cabe por el puente un caudal de $105,32 \mathrm{~m} / 3 / \mathrm{s}$. Este caudal equivale a un periodo de retorno de unos 40 años. No obstante, crecidas menores ya desbordarían aguas arriba y aguas abajo del puente, por lo que este valor es meramente informativo.

Al comparar la situación actual del cauce del río Turia en el puente de Hierro con la que tenía en junio de 1933, de acuerdo con las fotografías de la época, se observan las siguientes diferencias:

- En la actualidad hay abundante vegetación bajo el puente, aunque principalmente herbácea. En 1933 había vegetación en la ribera aguas abajo del puente, pero alejada unos 27 metros (coincidiendo con la salida de un desagüe en margen izquierda) de la infraestructura. El lecho era de gravas y carecía de vegetación y otros obstáculos.

- La morfología del lecho en 1933 era muy regular, homogeneizada, probablemente por la práctica de extracciones de áridos en la zona.

- A diferencia de la situación actual, se encontraba más abierto el arco de piedra de la margen izquierda que el de la derecha.

- En la mitad derecha del cauce, bajo el puente, la profundidad era $110 \mathrm{~cm}$ mayor que la actual, de acuerdo con los sillares visibles en el pilar del puente. En el canal de estiaje puede estimarse que la profundidad también era mayor en 1933, pero tan solo unos 20 $\mathrm{cm}$ respecto a la actual.

De acuerdo con las fotografías, en conjunto la sección del puente en 1933 puede estimarse en unos $110 \mathrm{~m}^{2}$, es decir, aproximadamente un $27 \%$ mayor que la sección actual. El radio hidráulico, con un perímetro de mojado estimado en 48 m, se situaría en 2,29. La pendiente local es imposible de estimar, por lo que aplicamos la misma que en la actualidad. La rugosidad sería inferior a la actual, en torno a 0,06 en una situación de crecida. La capacidad de caudal circulante bajo el puente sería en 1933 de $176,5 \mathrm{~m}^{3} / \mathrm{s}$, es decir, un $68 \%$ mayor que la capacidad actual.

Sin embargo, la crecida de 1933 no alcanzó el tablero del puente, sino que se quedó aproximadamente a $0,5 \mathrm{~m}$. Esto implica que la sección ocupada por la crecida puede estimarse en $95 \mathrm{~m}^{2}$. El radio hidráulico se situaría en 2,02. El caudal punta de la crecida, aplicando la fórmula de Manning, alcanzaría 140,2 m³ $/ \mathrm{s}$. Este valor es coincidente con el correspondiente a la crecida de 100 años según CAUMAX (SNCZI). Hay que tener en cuenta que éste es el caudal punta que pasaría por el puente, pero es posible que los flujos de desbordamiento lo incrementaran, ya que no se cuenta con información suficiente para determinar si la totalidad del caudal circuló por el puente. 

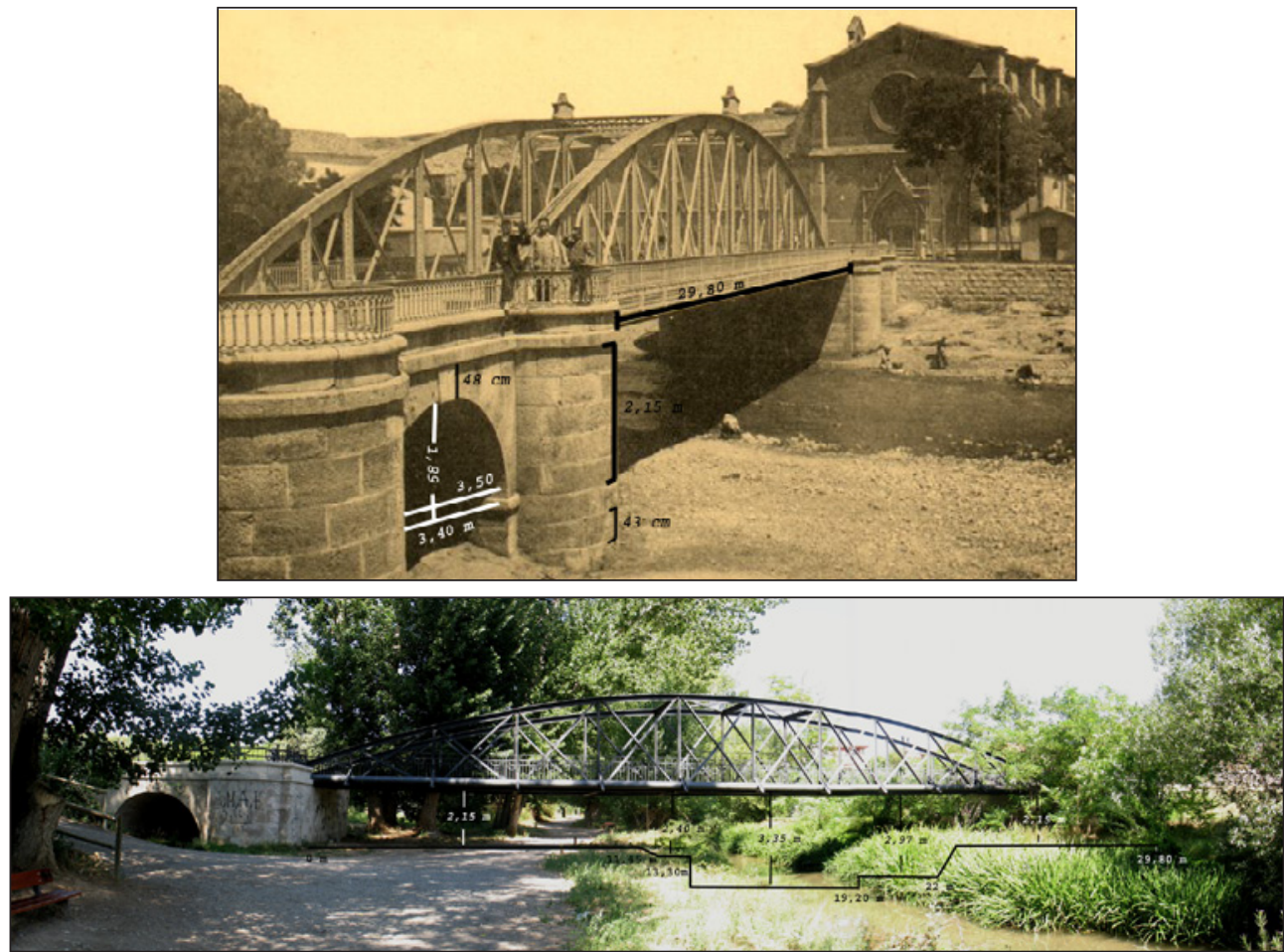

\section{CONCLUSIONES}

Del análisis efectuado se puede extraer una serie de conclusiones que corresponden tanto al plano metodológico como a los rasgos específicos de la crecida del río Turia en Teruel en junio de 1933.

La prensa escrita es un método muy adecuado y válido para detectar episodios de crecidas e inundaciones. Por ello, se ha utilizado con este fin desde hace mucho tiempo, aunque ahora su accesibilidad es más fácil ya que en algunos casos puede realizarse a través de internet. Además de servir para la detección de eventos de crecida, también aporta indicios sobre su magnitud y evolución, así como datos sobre la extensión del área inundada y los principales efectos socio-económicos. Estas pistas y datos cobran más valor si se puede efectuar comparación con otras crecidas extraordinarias con registros de caudal. También, si se producen en ámbitos donde ya está elaborada la Cartografía de Zonas Inundables con distintos periodos de retorno. La información que la prensa ofrece ayudaría a completar el actual Catálogo Nacional de Inundaciones Históricas y, por tanto, a definir con mayor precisión el nivel de riesgo de inundación de diferentes tramos de ríos. 
La crecida del río Turia en las proximidades de Teruel ha sido constatada en periódicos de ámbito local, regional y nacional. En ellos se han descrito daños materiales que llevan a pensar en una crecida de gran entidad. Esa entidad queda en primer lugar refrendada por el tratamiento recibido en las Actas de Reuniones del Ayuntamiento de Teruel y en las medidas que las autoridades competentes de la localidad solicitan al gobierno de la República, así como la rápida respuesta desde Madrid. También ratifica la magnitud de la crecida del Turia de 1933 el tratamiento que otros eventos han recibido en la citada prensa escrita. Sólo algunas entre las que alcanzaron mayores registros, desde 1956 hasta la actualidad, han quedado recogidas en los periódicos locales y regionales.

La crecida se generó por las abundantes precipitaciones, generalizadas en toda España, ligadas a la presencia de borrascas que recorren desde el norte la Península Ibérica. Hasta 99 mm en tres días, 78 de ellos en 36 horas, se midieron en Teruel. La respuesta de los ríos Alfambra, Guadalaviar y Turia, así como de las ramblas que atraviesan la propia ciudad de Teruel, fue muy rápida, alcanzándose el pico de la crecida durante la mañana del día 5 de junio, dentro del periodo de máxima intensidad de las precipitaciones iniciado la tarde anterior.

Los efectos de la crecida fueron múltiples: inundación de amplios sectores de vega con destrucción de cosechas, tráfico interrumpido en la carretera de Zaragoza y dificultad de tránsito de trenes en la propia ciudad de Teruel, destrozos en la avenida de Zaragoza, inundación del entorno de la iglesia-convento de San Francisco, arrastre de árboles, animales y restos de construcciones, hundimiento del puente de Doña Elvira o de Tablas... Conjuntamente evidencian, una vez más, la magnitud de la crecida. La superficie inundada se corresponde, por los datos recogidos en diferentes fuentes documentales, con la que el Sistema Nacional de Cartografía de Zonas Inundables (SNCZI-IPE) delimita para las crecidas con 50-100 años de retorno.

Combinando todos los datos anteriores se puede afirmar que la crecida de junio de 1933 es una de las mayores registradas por el Turia en Teruel, sólo comparable con las principales de las que se tienen registros de caudal máximo instantáneo. A partir del Mapa de Caudales Máximos (MAPAMA), de la fórmula de Gumbel y del método geomorfológico de estimación de caudal, se puede incluso evaluar su pico de caudal en torno a los $140 \mathrm{~m}^{3} / \mathrm{s}$.

La comparación entre la fotografía aérea del vuelo americano, serie A, de 1945/46 y la ortofoto de 2012 muestra claramente que los daños ocasionados por una crecida de igual magnitud a la acaecida en junio de 1933 serían muy superiores actualmente, ya que en el entorno de la avenida de Zaragoza y de la iglesia de San Francisco se han asentado instalaciones deportivas y se han incrementado sustancialmente las edificaciones. Además, la capacidad del cauce del Turia en puntos concretos, como es el caso del puente de Hierro, es considerablemente menor que la de 1933.

\section{BIBLIOGRAFÍA}

ACÍN, V., BALLARÍN, D., BRUFAO, P, DOMENECH, S., ESPEJO, F., GONZÁLEZHIDALGO, J.C., GRANADO, D., IBISATE, A., MARCÉN, C., MORA, D., NADAL, E., OLLERO, A., SÁNCHEZ-FABRE, M., SAZ, M.A. y SERRANO-NOTIVOLI, R. (2012): «Sobre las precipitaciones de octubre de 2012 en el Pirineo aragonés, su respuesta hidrológica y la gestión de riesgos». Geographicalia, n ${ }^{\circ}$ 61, 101-108. 
ALBEROLA, A. (2005): «Sequía, lluvias torrenciales y transporte fluvial de madera: las avenidas del río Turia del otoño de 1776». Revista de Historia Moderna, n 23, 49-74.

BARREDO, J.I. (2007): «Major flood disasters in Europe: 1950-2005». Nat. Hazards, $\mathrm{n}^{\circ}$ 42, 125-148.

BARRIENDOS, M. y RODRIGO, F.S. (2006): «Study of historical flood events on Spanish rivers using documentary data». Hydrological Sciences Journal, $\mathrm{n}^{\circ}$ 51:5,765-783.

BESCÓS, A. (2003): Las inundaciones en el río Arga: estudio hidrogeomorfológico. Tesis doctoral. Departamento de Geografía, Universidad de Alcalá.

BESCÓS, A. y CAMARASA, A. M. (2004): «La creciente ocupación antrópica del espacio inundable y el aumento de la vulnerabilidad en las poblaciones del bajo Arga (Navarra)». Boletín de la A. G. E., no 37, 101-117.

BORMANN, H., PINTER, N. y ELFERT, S. (2011): «Hydrological signatures of flood trends on German rivers: Flood frequencies, flood heights and specific stages» Journal of Hydrology, $\mathrm{n}^{\circ}$ 404, 50-65.

BRÁZDIL, R., KUNDZEWICZ, Z. W. y BENITO, G. (2006): «Historical hydrology for studiying flood risk in Europe». Hydrological Sciences Journal, nº 51:5, 739-764.

BÜRGER, K., DOSTAL, P., SEIDEL, J., IMBERY, F., BARRIENDOS, M., MAYER, H. y GLASER, R. (2006): «Hydrometeorological reconstruction of the 1824 flood event in the Neckar River basin (southweest Germany)». Hydrological Sciences Journal, $\mathrm{n}^{\circ}$ 51:5, 864-877

CARMONA, P. y RUIZ-PÉREZ, J.M. (2000): «Las inundaciones de los ríos Júcar y Turia». Serie Geográfica, no 9, 49-69.

CHASTAGNARET, G. y GIL OLCINA, A. (2006): Riesgo de inundaciones en el Mediterráneo occidental. Casa de Velázquez y Universidad de Alicante.

CHE (2014): Proyecto de Plan de gestión del riesgo de inundación. Documento borrador. Demarcación Hidrográfica del Ebro. Confederación Hidrográfica del Ebro, Ministerio de Agricultura, Alimentación y Medio Ambiente.

COEUR, D. y LANG, M. (2008): «Use of documentary sources on past flood events for flood risk management and land planning». Science Direct. C.R. Geoscience, $\mathrm{n}^{\circ} 340$, 644-650.

DEMARÉE, G.R. (2006): «The catastrophic floods of February 1784 in and around Belgium - a Little Ice Age evente of frost, snow, river ice....and floods». Hydrological Sciences Journal, ${ }^{\circ}$ 51:5, 878-898.

DEL VALLE, J., OLLERO, A. y SÁNCHEZ FABRE, M. (2007): Atlas de los ríos de Aragón. Ed. Prames. 476 p. Zaragoza

DIRECCIÓN GENERAL DE PROTECCIÓN CIVIL Y EMERGENCIAS (2014): Catálogo Nacional de Inundaciones Históricas. Ministerio del Interior. Gobierno de España. DVD.

ESPEJO, F. (2008): «Hacia una tipología de inundaciones en la cuenca del Ebro en función de sus causas atmosféricas». Geographicalia, n ${ }^{\circ}$ 53, 73-100.

ESPEJO, F., DOMENECH, S., OLLERO, A. y SÁNCHEZ-FABRE, M. (2008): «La crecida del Ebro de 2007: procesos hidrometeorológicos y perspectivas de gestión del riesgo». Boletín de la A.G.E., $\mathrm{n}^{\circ} 48,129-154$. 
GALLART, F. (1988) «Método pendiente-área» en Métodos y técnicas para la medición en el campo de procesos geomorfológicos (Sala, M. y Gallart, F., eds.) Barcelona, Sociedad Española de Geomorfología, 66-70.

GALVÁN, R., DEL VALLE, J., LOSADA, J.A. y ARNAL, M. (2013): «La inundación del Ebro de 1871 en Zaragoza». Boletín de la Real Sociedad Geográfica, CXLIX, 139-169.

GARCÍA-RUIZ, J.M., PUIGDEFÁBREGAS, J. y MARTÍN-RANZ, M.C. (1983): «Diferencias espaciales en la respuesta hidrológica a las precipitaciones torrenciales de noviembre de 1982 en el Pirineo Central». Estudios Geográficos, nº 170-171, 291-316.

GARCÍA-RUIZ, J.M., WHITE, S., MARTÍ, C., VALERO, B., ERREA, M.P. y GÓMEZ VILLAR, A. (1996): La catástrofe del barranco de Arás (Biescas, Pirineo Aragonés) y su contexto espacio-temporal. Instituto Pirenaico de Ecología, 54 p., Zaragoza.

GARCÍA-RUIZ, J.M., ARNÁEZ, J., WHITE, S. y BORDONABA, A.P. (1998): «Predicción de eventos extremos en áreas de montaña. El ejemplo del Pirineo Central» en Investigaciones recientes de la Geomorfología española (Gómez Ortiz, A. y Salvador, F., eds.). Barcelona, Sociedad Española de Geomorfología, 623-630.

GARCÍA-RUIZ, J.M., BEGUERÍA, S. y LORENTE, A. (2000): «Eventos hidrológicos de baja frecuencia en el Pirineo central español y sus efectos geomorfológicos». Serie Geográfica, nº 9, 163-176.

GARCÍA-RUIZ, J.M., BEGUERÍA, S., LÓPEZ-MORENO, J.I., LORENTE, A. y SEEGER, M. (2001): Los recursos hídricos superficiales del Pirineo aragonés y su evolución reciente. Logroño, Geoforma Ediciones.

GAUME, E., BAIN, V., BERNARDARA, P., NEWINGER, O., BARBUC, M., BATEMAN, A., BLAŠKOVIČOVÁ, L., BLÖSCHL, G., BORGA, M., DUMITRESCU, A., DALIAKOPOULOS, I., GARCIA, J., IRIMESCU, A., KOHNOVA, S., KOUTROULIS, A., MARCHI, L., MATREATA, S., MEDINA, V., PRECISO, E., SEMPERE-TORRES, D., STANCALIE, G., SZOLGAY, J., TSANIS, I., VELASCO, D. y VIGLIONE, A. (2009): «A compilation of data on European flash floods». Journal of Hydrology, $\mathrm{n}^{\circ} 367,70-78$.

GLASER, R. y STANGL, H. (2003): «Historical floods in the Dutch Rhine Delta». Natural Hazards and Earth System Sciences, 605-613. European Geosciences Union.

GLASER, R., RIEMANN, D., SCHÖNBEIN, J., BARRIENDOS, M., BRÁZDIL, R., BERTOLIN, C., CAMUFFO, D., DEUTSCH, M., DOBROVOLNÝ, P., VAN ENGELEN, A., ENZI, S., HALÍČKOVÁ, M., KOENIG, S.J., KOTYZA, O., LIMANÓWKA, D., MACKOVÁ, J., SGHEDONI, M., MARTIN, B. y HIMMELSBACH, I. (2010): «The variability of European floods since AD 1500». Climatic Change, $\mathrm{n}^{\circ} 101,235$ 256.

GUILLÉN, M.P. (2001): Las cuencas fluviales turolenses. Tesis Doctoral (inédita). Departamento de Geografía y Ordenación del Territorio, Univ. de Zaragoza. 639 págs. y anexo cartográfico.

IBISATE, A., OLLERO, A. y ORMAETXEA, O. (2000): «Las inundaciones en la vertiente cantábrica del Pais Vasco en los últimos veinte años: principales eventos, consecuencias territoriales y sistemas de prevención». Serie Geográfica, nº 9, 177-186. 
KOTLARSKI, S., HAGEMANN, S., KRAHE, P., PODZUN, R. y JACOB, D. (2012): «The Elbe river flooding 2002 as seen by and extended regional climate model». Journal of Hydrology, $\mathrm{n}^{\circ}$ 472-473, 169-183.

KOUTROULIS, A. y TSANIS, I. (2010): «A method for estimating flash flood peak discharge in a poorly gauges basin: Case study for the 13 - 14 January 1994 flood, Giofiros basin, Crete, Greece». Journal of Hydrology, $\mathrm{n}^{\circ}$ 385, 150-164.

KUNDZEWICZ, Z.W., PINSKWAR, I. y BRAKENRIDGE, R. (2012): «Large floods in Europe, 1985-2009». Hydrological Sciences Journal, $\mathrm{n}^{\circ}$ 1, 1-7.

LEHNER, B., DÖLL, P., ALCAMO, J., HENRICHS, T. y KASPAR, F. (2006): «Estimating the impact of global change on flood and drought risks in Europe: A continental, integrated analysis». Climatic Change, $\mathrm{n}^{\circ}$ 75, 273-299.

LÓPEZ-MORENO, J.I., BEGUERÍA, S. y GARCÍA-RUIZ, J.M. (2006): «Trends in high flows in the central Spanish Pyrenees: response to climatic factor sor to land-use change?». Hydrological Sciences Journal, nº 51:6, 1039-1050.

LOSADA, J.A., MONTESINOS, S., OMEDAS, M., GARCÍA VERA, M.A. y GALVÁN, R. (2004): «Cartografía de las inundaciones del río Ebro en febrero de 2003: trabajos de fotointerpretación, teledetección y análisis SIG en el GIS-Ebro» en Medio ambiente, recursos y riesgos naturales: análisis mediante tecnología SIG y teledetección (Conesa, C., Álvarez, Y. y Martínez, J.B., eds.). Universidad de Murcia, 207-218.

MARCHI, L., BORGA, M., PRECISO, E. y GAUME, E. (2010): «Characterisation of selected extreme flash floods in Europe and implications for flood risk management». Journal of Hydrology, $\mathrm{n}^{\circ}$ 394, 118-133.

MARQUÍNEZ, J., FERNÁNDEZ-IGLESIAS, E., ARNAL, J.M. y MORENO, M.L. (2014): «Reactivación del cauce histórico del río Ésera por la avenida de junio de 2013 (Pirineo Central)». XIII Reunión Nacional de Geomorfología, 115-118.

MATEU, J.F., RUIZ, J.M. y PORTUGUÉS, I. (2012): Desarrollo del servicio de aforos en España. La red de estaciones de la Confederación Hidrográfica del Júcar. Valencia, Confederación Hidrográfica del Júcar.

MINISTERIO DEL AIRE (1942): Resumen de observaciones meteorológicas de 1933. Servicio Meteorológico Nacional.

MORELL, J. (1999): Les revingudes de la conca alta del Turia. Memoria de licenciatura (inédita). Departamento de Geografía. Universitat de València. 241 págs.

MORELL, J. (2001): «El factor de la precipitación en la formación de avenidas en la cuenca alta del Turia». Geographicalia, $\mathrm{n}^{\circ}$ 40, 47-74.

OLCINA, J. (2006): «Reducción del riesgo de inundaciones en el litoral mediterráneo español. El papel de la ordenación del territorio» en Riesgo de inundaciones en el Mediterráneo occidental (Chastagnaret, G. y Gil Olcina, A., dirs). Casa de Velázquez y Universidad de Alicante, 157-214.

OLLERO, A. (1992): Los meandros libres del Ebro medio (Logroño-La Zaida): geomorfología fluvial, ecogeografía y riesgos. Tesis doctoral. Dpto. de Geografía y Ordenación del Territorio, Universidad de Zaragoza.

OLLERO, A. (2006): «Inundaciones y ordenación del territorio fluvial en la cuenca del Ebro» en Riesgo de inundaciones en el Mediterráneo occidental. (Chastagnaret, G. y Gil Olcina, A., dirs.) Casa de Velázquez y Universidad de Alicante, 239-272. 
OLLERO, A. (2007): Territorio fluvial. Diagnóstico y propuesta para la gestión ambiental $y$ de riesgos en el Ebro y los cursos bajos de sus afluentes. Bilbao, Bakeaz y Fundación Nueva Cultura del Agua.

OLLERO, A. (2014): Guía metodológica sobre buenas prácticas en gestión de inundaciones. Manual para gestores. Contrato de río del Matarraña, ECODES, 143 p., Zaragoza.

OLLERO, A., PELLICER, F. y SÁNCHEZ-FABRE, M. (2004): «La crecida de febrero de 2003 en el curso medio del Ebro: análisis de su evolución espacio-temporal» en Aportaciones geográficas en homenaje al Profesor Antonio Higueras Arnal (Faus, M.C., ed.) Zaragoza, Universidad de Zaragoza, 143-55.

PÉREZ MORALES, A. y GIL, S. (2012): «La avenida de 22 de octubre de 1948 en la cuenca del Segura. Revisión y análisis». Estudios Geográficos, vol. LXXIII, 272, 163-187.

PETROW, T. y MERZ, B. (2009): «Trends in flood magnitude, frequency and seasonality in Germany in the period 1951 - 2002». Journal of Hydrology, ${ }^{\circ} 371,129-141$.

RATTO, S., BONETTO, F. y COMOGLIO, C. (2003): «The October 2000 flooding in Valle d'Aosta (Italy): event description and land planning measures for the risk mitigation». International Journal of River Basin Management, $\mathrm{n}^{\circ} 1$ (1), 105-116.

ROMERO, A. y MAURANDI, A. (2000): «Las inundaciones en la cuenca del Segura en las dos últimas décadas del siglo XX. Actuaciones de prevención». Serie Geográfica, $\mathrm{n}^{\circ}$ 9, 93-120.

SÁNCHEZ FABRE, M. (1993): «Aportación al estudio hidrológico del río Alfambra (prov. de Teruel)». Geographicalia, n 30, 347-360.

SÁNCHEZ FABRE, M.; PEÑA, J.L. y MOYA, C. (1986): «Aportación al conocimiento del régimen fluvial de los ríos Alfambra y Guadalaviar o Turia a su paso por Teruel». Teruel, $\mathrm{n}^{\circ}$ 76, 27- 49.

SÁNCHEZ FABRE, M.; OLLERO, A. y LOZANO, M.V. (2008): «El río Guadalaviar: su comportamiento hidrológico». Rehalda, $\mathrm{n}^{\circ}$ 7, p. 37-52.

SÁNCHEZ FABRE, M.; OLLERO, A., MORA, D., DEL VALLE, J. y BALLARÍN, D. (2013): Los ríos de la provincia de Teruel. Instituto de Estudios Turolenses, 60 p.

SERRANO-NOTIVOLI, R., MORA, D., OLLERO, A., SÁNCHEZ-FABRE, M. y SAZ, M.A. (2014): «Respuesta hidrológica al evento de precipitación de junio de 2013 en el Pirineo Central». Investigaciones Geográficas, $\mathrm{n}^{\circ}$ 62, 5-21.

SERRANO-MUELA, M.P., NADAL-ROMERO, E., LANA-RENAULT, N., GONZÁLEZHIDALGO, J.C., LÓPEZ-MORENO, J.I., BEGUERÍA, S., SANJUAN, Y. y GARCÍARUIZ, J.M. (2013): «An exceptional rainfall event in the central western Pyrenees: Spatial patterns in discharge and impact». Land Degradation \& Development, $\mathrm{n}^{\circ} 26$ (3), 249-262.

TAROLLI, P., BORGA, M., MORIN, E. y DELRIEU, G. (2012): «Analysis of flash flood regimes in the North-Western and South-Eastern Mediterranean regions». Natural Hazard and Earth System Sciences, ${ }^{\circ}$ 12, 1255-1265.

TERRANOVA, O.G. y GARIANO, S.L. (2014): «Rainstorms able to induce flash floods in a Mediterranean-climate region (Calabria, southern Italy)». Natural Hazards and Earth System Sciences, ${ }^{\circ}$ 14, 2423-2434.

VV.AA. (2012): «Agua, Ingeniería y Territorio: Los ríos Júcar y Turia (1930-1959)». Cuadernos de Geografía, n 91-92. 


\section{OTRAS FUENTES}

ARCHIVO MUNICIPAL DEL AYUNTAMIENTO DE TERUEL: Actas de Sesiones.

BIBLIOTECA VIRTUAL DE ARAGÓN DE LA BIBLIOTECA DE ARAGÓN. http:// bibliotecavirtual.aragon.es/bva/i18n/consulta/busqueda.cmd

BIBLIOTECA VIRTUAL DE PRENSA HISTÓRICA DE LA BIBLIOTECA NACIONAL. http://prensahistorica.mcu.es/es/consulta/busqueda.cmd

HEMEROTECA MUNICIPAL DE TERUEL: Diario de Teruel, Heraldo de Aragón.

HEMEROTECA MUNICIPAL DE ZARAGOZA: Diario de Teruel, El Periódico de Aragón, Heraldo de Aragón.

MINISTERIO DE AGRICULTURA, PESCA, ALIMENTACIÓN Y MEDIO AMBIENTE (MAPAMA): Sistema de Información del Anuario de Aforos. http://sig.mapama.es/redesseguimiento/visor.html

MINISTERIO DE AGRICULTURA, PESCA, ALIMENTACIÓN Y MEDIO AMBIENTE (MAPAMA): Sistema Nacional de Cartografía de Zonas Inundables (SNCZI). http://sig. mapama.es/snczi/visor.html

WETTERZENTRALE. http://www.wetterzentrale.de./ 